\title{
Buffering Agent via Insulin-Mediated Activation of PI3K/AKT Signaling Pathway to Regulate Lipid Metabolism in Lactating Goats
}

\author{
Lin LI ${ }^{1}$, Mei Lin HE ${ }^{1}$, Kai WANG ${ }^{1}$, Yuan Shu ZHANG ${ }^{1}$ \\ ${ }^{1}$ Key Laboratory of Animal Physiology and Biochemistry, Ministry of Agriculture, Nanjing \\ Agricultural University, Nanjing, People's Republic of China
}

Received June 23, 2017

Accepted May 14, 2018

On-line July 25, 2018

\section{Summary}

Ruminants are often fed a high-concentrate $(\mathrm{HC})$ diet to meet lactating demands, yet long-term concentrate feeding induces subacute ruminal acidosis (SARA) and leads to a decrease in milk fat. Buffering agent could enhance the acid base buffer capacity and has been used to prevent ruminant rumen SARA and improve the content of milk fat. Therefore, we tested whether a buffering agent increases lipid anabolism in the livers of goats and influences of milk fat synthesis. Twelve Saanen-lactating goats were randomly assigned to two groups: one group received a HC diet (Concentrate: Forage $=60: 40$, Control) and the other group received the same diet with a buffering agent added $(10 \mathrm{~g}$ sodium butyrate, $\mathrm{C}_{4} \mathrm{H}_{7} \mathrm{NaO}_{2} ; 10 \mathrm{~g}$ sodium bicarbonate, $\mathrm{NaHCO}_{3}$; BG) over a 20-week experimental period. Overall, milk fat increase $(4.25 \pm 0.08$ vs. $3.24 \pm 0.10 ; \quad P<0.05)$, and lipopolysaccharide levels in the jugular $(1.82 \pm 0.14$ vs. $3.76 \pm 0.33)$ and rumen fluid $(23,340 \pm 134$ vs. $42,550 \pm 136)$ decreased in the buffering agent group $(P<0.05)$. Liver consumption and release of nonesterified fatty acid (NEFA) into the bloodstream increased $(P<0.05)$. Phosphatidylinositol 3-kinase (PI3K), protein kinase $B$ (AKT) and ribosomal protein S6 kinase (p70S6K) up-regulated significantly in the livers of the buffering agent group $(P<0.05)$. It also up-regulated expression of the transcription factor sterol regulatory element binding protein-1C (SREBP-1C) and its downstream targets involved in fatty acid synthetic, including fatty acid synthetase (FAS), stearoyl-CoA desaturase (SCD-1) and acetyl-CoA carboxylase 1 (ACC1) $(P<0.05)$. The BG diet increased insulin levels in blood $(19.43 \pm 0.18$ vs. $13.81 \pm 0.10, P<0.05)$, and insulin receptor was likewise elevated in the liver $(P<0.05)$. Cumulatively, the BG diet increased plasma concentrations of NEFA by INS-PI3K/AKTSREBP-1c signaling pathway promoting their synthesis in the liver. The increased NEFA concentration in the blood during BG feeding may explain the up-regulated in the milk fat of lactating goats.

\section{Key words}

High-concentrate diet $\bullet \mathrm{C}_{4} \mathrm{H}_{7} \mathrm{NaO}_{2} \bullet \mathrm{NaHCO}_{3} \bullet \mathrm{PI} 3 \mathrm{~K} / \mathrm{AKT}$ signaling pathway $\bullet$ Lipid metabolism

\section{Corresponding author}

Y. S. Zhang, Key Laboratory of Animal Physiology and Biochemistry, College of Veterinary Medicine, Nanjing Agricultural University, Nanjing 210095, People's Republic of China. Fax: +86-2584395335. E-mail: zhangyuanshu@njau.edu.cn

\section{Introduction}

Ruminants are often fed a high-concentrate (HC) diet to meet lactating requirements for high milk performance (Gozho et al. 2005). However, long-term feeding with a $\mathrm{HC}$ diet causes a decline in the rumen $\mathrm{pH}$ if organic acids, such as lactic acid and volatile fatty acids, accumulate in the rumen, and a chronic digestive disorder known as subacute ruminal acidosis (SARA) may occur (Plaizier et al. 2008, Chen and Oba 2012). In experimental study, ruminal $\mathrm{pH}$ value $<5.6$ lasted more than $3 \mathrm{~h}$ was considered as the critical value of SARA diagnosis (Gozho et al. 2005). Moreover, previous studies have shown that lactating goats fed a $\mathrm{HC}$ diet induced a SARA, which was characterized by inflammation and depressed milk fat (Khafipour et al. 2009). It has been reported that the feeding of $\mathrm{HC}$ diets to lactating cows results in the release of lipopolysaccharide (LPS) from 
the rumen or hindgut (Zebeli and Ametaj 2009). Meanwhile, previous studies have shown that LPS can translocate into the bloodstream from the digestive tract under conditions of high permeability and after injury to the liver organ (Khafipour et al. 2016).

Milk fat is an important nutritional ingredient of milk that is beneficial to human health. However, long-term feeding with a $\mathrm{HC}$ diet induces a reduction in milk fat (Zebeli et al. 1999). Triglycerides (TG) are the main component of milk fat and are synthesized using fatty acids and $\alpha$-glycerophosphate in mammary epithelial cells (Pennington et al. 1952). The uptake of nonesterified fatty acid (NEFA) components by mammary glands is affected by their concentrations in the blood. Previous studies have shown that with an increasing NEFA content in the blood, the absorbed quantity applied to milk fat synthesis was also elevated in mammary cells (Bauman et al. 2011). Therefore, the substrate precursor of NEFA plays a crucial physiological role in milk fat synthesis. Nutrients required for milk synthesis must be transported from the rumen and gut to the liver to undergo metabolic conversion. In ruminants, the liver is the major site of lipid metabolism and gluconeogenesis, which provides the substrate precursors to the mammary gland for milk production. Liver lipidolysis and lipid synthesis rely on the absorption and utilization of NEFA in the blood (Bell 1979, Kristensen 2005). NEFA are transported through the hepatic portal vein into the liver, where they are metabolized. Then, they exit the liver through the hepatic vein, where they are taken up into the blood.

Buffering agent could enhance the acid base buffer capacity and has been used to prevent ruminant rumen SARA and improve the production performance. It is well documented that dietary addition of sodium butyrate $\left(\mathrm{C}_{4} \mathrm{H}_{7} \mathrm{NaO}_{2}\right)$ could enhance solid feed intake, rumen development and health status of neonatal calves (Meng et al. 1999). In addition, dietary addition of $2 \%$ sodium bicarbonate $\left(\mathrm{NaHCO}_{3}\right)$ could increase the buffering capacity and prevent the acidosis in rumen (Gorka et al. 2009). Previous studies indicated that the addition of $\mathrm{NaHCO}_{3}$ to a restricted-roughage rations could be given to lactating cows to increase the content of milk fat (Islam et al. 2014). However, at present, the research of buffering agent is focused on the milk production and composition of dairy cows. Furthermore, little is known regarding the mechanism of how a buffering agent improves milk fat metabolism in goats. In this study, we created a buffering agent consisting of $\mathrm{NaHCO}_{3}$ and $\mathrm{C}_{4} \mathrm{H}_{7} \mathrm{NaO}_{2}$ and mixed it with a $\mathrm{HC}$ diet source that was fed to lactating goats. We then investigated the effect of these buffering agent on the development of SARA and milk fat production to elucidate potential mechanisms for this phenomenon.

\section{Methods}

\section{Ethical approval}

All animal procedures were approved by the Institutional Animal Care and Use Committee of Nanjing Agricultural University. The protocols were reviewed and approved, and the project number 2011CB100802 was assigned. The slaughter and sampling procedures strictly followed the 'Guidelines on Ethical Treatment of Experimental Animals' (2006) no. 398 established by the Ministry of Science and Technology, China and the 'Regulation regarding the Management and Treatment of Experimental Animals' (2008) no. 45 set by the Jiangsu Provincial People's Government.

\section{Animal and experimental procedures}

A total of twelve healthy multiparous midlactating goats (body weight, $38 \pm 8 \mathrm{~kg}$, mean \pm SEM, 3-5 weeks post-partum) at the age of 2-3 years were used in experiments. They were housed in individual stalls in a standard animal feeding house at Nanjing Agricultural University (Nanjing, China). Goats were randomly divided into two groups: high-concentrate diet group (Control, concentrate: forage $=60: 40)$ and buffering agent group $(\mathrm{BG}$, concentrate: forage $=60: 40$ with $10 \mathrm{~g} \mathrm{C}_{4} \mathrm{H}_{7} \mathrm{NaO}_{2}$ and $10 \mathrm{~g}$ $\mathrm{NaHCO}_{3}$ ), six in each group. Dietary $\mathrm{C}_{4} \mathrm{H}_{7} \mathrm{NaO}_{2}$ and $\mathrm{NaHCO}_{3}$ were obtained from Nanjing Jiangcheng Bioengineering Institute, China). The ingredients and nutritional composition of the diets are presented in Table 1. The goats were fitted with a rumen fistula and hepatic catheters two weeks before the experiment and were ensured that they recovered from the surgery. Animals were monitored for 2 weeks after surgery. Sterilized heparin saline $(500 \mathrm{IU} / \mathrm{ml}, 0.3 \mathrm{ml} /$ time $)$ was administered at 8-hour intervals every day until the end of the experiment to prevent catheters from becoming blocked. During the experimental period of 20 weeks, goats were fed two times daily at 8.00 and 18.00 , had free access to fresh water, and the feed amount met or exceeded the animal's nutritional requirements. The Institutional Animal Care and Use Committee of Nanjing Agricultural University (Nanjing, People's Republic of China) approved all of the procedures (surgical procedures and care of goats). 
Table 1. Ingredients and nutritional composition of the diets.

\section{Concentrate: Forage ratio 60:40}

\begin{tabular}{lc|lc}
\hline Ingredient (\%) & & Nutrient levels & \\
Leymus chinensis & 27.00 & Net energy/(MJ.kg & \\
Alfalfa silage & 13.00 & Crude protein/\% & 6.71 \\
Corn & 23.24 & Neutral detergent fiber/\% & 16.92 \\
Wheat bran & 20.77 & Acid detergent fiber/\% & 31.45 \\
Soybean meal & 13.67 & Calcium/\% & 17.56 \\
Limestone & 1.42 & Phosphorus $/ \%$ & 0.89 \\
NaCl & 0.30 & & 0.46 \\
Premix & & \\
Total & 0.60 & & \\
\hline
\end{tabular}

a - Provided per kg of diet: VA 6,000 IU/kg, VD 2,500 IU/kg, VE $80 \mathrm{mg} / \mathrm{kg}, \mathrm{Cu} 6.25 \mathrm{mg} / \mathrm{kg}, \mathrm{Fe} 62.5 \mathrm{mg} / \mathrm{kg}, \mathrm{Zn} 62.5 \mathrm{mg} / \mathrm{kg}$, $\mathrm{Mn} 50 \mathrm{mg} / \mathrm{kg}$, I $0.125 \mathrm{mg} / \mathrm{kg}$, Co $0.125 \mathrm{mg} / \mathrm{kg} .{ }^{{ }^{\prime}}$ - Nutrient levels were according to National Research Council (NRC 2001).

\section{Milk composition analysis}

We collected 50-ml samples of fresh milk into vials with potassium dichromated every week, and the milk fat, protein, total solids and lactose concentrations in the samples was analyzed using the Integrated MilkTesting ${ }^{\mathrm{TM}}$ Milkoscan 4000 (Foss Electric, Hillerod, Denmark) at the Animal Experiment Center of College of Animal Science and Technology at the Nanjing Agricultural University.

\section{Rumen fluid collection and analysis}

Rumen fluid was sampled at the last day of weeks 17,18 and 19 through a cannula from the ventral sac of the rumen after mixing the content at $0 \mathrm{~h}, 2 \mathrm{~h}, 4 \mathrm{~h}$, $6 \mathrm{~h}, 8 \mathrm{~h}, 10 \mathrm{~h}$ and $12 \mathrm{~h}$ after feeding, $20 \mathrm{ml}$ rumen fluids was collected with a nylon bag and the $\mathrm{pH}$ value was measured immediately with $\mathrm{pH}-$-meter. The rumen fluid was collected and each sample was transferred into a 50-ml sterile tube and kept on ice until transported to the laboratory for the initial processing before LPS determination.

The concentration of LPS in rumen fluid was measured by a Chromogenic End-point Tachypleus Amebocyte Lysate Assay Kit (CE64406, Chinese Horseshoe Crab Reagent Manufactory Co., Ltd., Xiamen, China). Pretreated rumen fluid samples were diluted until their LPS concentrations were in the range of 0.1-1.0 endotoxin units $(\mathrm{EU}) / \mathrm{ml}$ relative to the reference endotoxin.

\section{Measurement of plasma biochemical parameters}

At the end of the experiment, plasma was sampled thirty minutes prior to feed delivery using EDTA-containing vacuum tubes from the jugular, hepatic and portal veins. Blood was centrifuged at $2,500 \times \mathrm{g}$ for $10 \mathrm{~min}$ to separate the plasma. Plasma glucose, TG, NEFA and total cholesterol were quantified using a Beckman Kurt AU5800 series automatic biochemical analyzer (Beckman Kurt, USA) at the General Hospital of Nanjing Military Region (Nanjing, China). The concentration of INS and glucagon in the plasma were determined by ELISA kits (Shanghai Enzyme-linked Biotechnology Co. Ltd, Shanghai, China). The detected range of ELISA kits for insulin (INS) and glucagon were $0.1-40 \mathrm{mIU} / 1$ and $5-1,000 \mathrm{pg} / \mathrm{ml}$, respectively. The procedures were performed according to the manufacturer's instructions.

The LPS concentration were determined using a chromogenic endpoint assay (CE64406, Chinese Horseshoe Crab Reagent Manufactory Co., Ltd., Xiamen, China) The procedures were performed according to the manufacturer's instructions.

\section{Sample collection}

After 20 weeks, goats were slaughtered after overnight fasting. All goats were killed with neck vein injections of xylazine $(0.5 \mathrm{mg} / \mathrm{kg}$ body weight; Xylosol; Ogris Pharme, Wels, Austria) and pentobarbital $(50 \mathrm{mg} / \mathrm{kg}$ body weight; Release; WDT, Garbsen, Germany). After slaughter, liver tissue was collected and washed twice with cold physiological saline $(0.9 \% \mathrm{NaCl})$ to remove blood and other contaminants. Livers were then transferred into liquid nitrogen and used for RNA and protein extraction. 
RNA extraction, $c D N A$ synthesis and quantitative realtime PCR ( $q R T-P C R$ )

Relative mRNA expression in liver tissue was measured by qRT-PCR using the $2^{-\Delta \Delta^{\mathrm{Ct}}}$ method. Briefly, total RNA was extracted from liver samples using TRIzol reagent (Invitrogen, USA) and converted to cDNA using commercial kits (Vazyme, Nanjing, China). All PCR primers were synthesized by Generay Company
(Shanghai, China), and the primer sequences are listed in Table 2. PCR was performed using the AceQ qPCR SYBR Green Master Mix kit (Vazyme, Nanjing, China) and the MyiQ2 Real-time PCR system (Bio-Rad, USA) with the following cycling conditions: $95^{\circ} \mathrm{C}$ for $2 \mathrm{~min}$, 40 cycles of $95^{\circ} \mathrm{C}$ for $15 \mathrm{~s}$ and $60{ }^{\circ} \mathrm{C}$ for $30 \mathrm{~s}$. Glyceraldehyde 3-phosphate dehydrogenase (GAPDH) served as reference for normalization.

Table 2. Primer sequences used for qRT-PCR analysis of target genes in lactating goats.

\begin{tabular}{|c|c|c|}
\hline Target genes & Primer sequences (5'-3') & Products/bp \\
\hline$C P T-1$ & $\begin{array}{l}\text { CCCATGTCCTTGTAATGAGCCAG } \\
\text { AGACTTCGCTGAGCAGTGCCA }\end{array}$ & 230 \\
\hline$C P T-2$ & $\begin{array}{l}\text { ACGCCGTGAAGTATAACCCT } \\
\text { CCAAAAATCGCTTGTCCCTT }\end{array}$ & 119 \\
\hline$L-F A B P$ & $\begin{array}{l}\text { AATACCAAGTCCAGACCCAG } \\
\text { CACGATTTCCGACACCC }\end{array}$ & 110 \\
\hline$A C O$ & $\begin{array}{c}\text { TAAGCCTTTGCCAGGTATT } \\
\text { ATGGTCCCGTAGGTCAG }\end{array}$ & 189 \\
\hline PPAR & $\begin{array}{c}\text { GGAGGTCCGCATCTTCCACT } \\
\text { GCAGCAAATGATAGCAGCCACA }\end{array}$ & 352 \\
\hline$F A S$ & $\begin{array}{c}\text { GCACTACCACAACCCAAACCC } \\
\text { CGTTGGAGCCACCGAAGC }\end{array}$ & 161 \\
\hline$A C C 1$ & $\begin{array}{l}\text { ACGCAGGCATCAGAAGATTA } \\
\text { GAGGGTTCAGTTCCAGAAAGTA }\end{array}$ & 179 \\
\hline$S C D-1$ & $\begin{array}{c}\text { CCGCCCTGAAATGAGAGATG } \\
\text { AGGGCTCCCAAGTGTAACAGAC }\end{array}$ & 154 \\
\hline$S R E B P-1 c$ & $\begin{array}{c}\text { CGACTACATCCGCTTCCTTCA } \\
\text { ACTTCCACCGCTGCTACTG }\end{array}$ & 259 \\
\hline$I R S$ & $\begin{array}{c}\text { GGCAGTCCTGTGAGTCCTA } \\
\text { AAGGCGAGCAGCGAGAA }\end{array}$ & 124 \\
\hline$I N S R$ & $\begin{array}{c}\text { CACACAGCCACTGCCAGAAAGGG } \\
\text { AGAAACCGAGTGCGGACCGC }\end{array}$ & 151 \\
\hline$G A P D H$ & $\begin{array}{l}\text { GGGTCATCATCTCTGCACCT } \\
\text { GGTCATAAGTCCCTCCACGA }\end{array}$ & 177 \\
\hline
\end{tabular}

\section{Western blotting}

Total protein was extracted from frozen liver tissue, and the concentration was determined using the bicinchoninic acid (BCA) assay (Pierce, Rockford, IL, USA). We isolated $30 \mu \mathrm{g}$ of protein from each sample, which was subjected to electrophoresis on a SDS-PAGE. The separated proteins were transferred onto nitrocellulose membranes (Bio Trace, Pall Co., USA). The blots were incubated with the following Cell Signaling Technology primary antibodies for overnight at $4{ }^{\circ} \mathrm{C}$ with a dilution of $1: 1,000$ in block: rb-anti- phosphatidylinositol 3-kinase (rb-anti-PI3K, \#4249S), rb-anti-protein kinase B (rb-anti-AKT, \#9272S), rb-antiPhosphorylated protein kinase B (rb-anti-P-AKT, \#4060S), rb-anti-ribosomal protein S6 kinase (rb-antip70S6K, \#9204S), rb-anti-Phosphorylated ribosomal protein S6 kinase (rb-anti-P-p70S6K, \#9202S), rb-antiacetyl-CoA carboxylase 1 (rb-anti-ACC1, \#3662S), rb-anti-Phosphorylated acetyl-CoA carboxylase 1 (rb-anti-P-ACC1, \#3661S). A rb-anti-GAPDH primary antibody (a531, Bioworld, China, 1: 10,000) was also incubated with the blots to provide a reference for 
normalization. After washing the membranes, an incubation with HRP-conjugated secondary antibody was performed for $2 \mathrm{~h}$ at room temperature. Finally, the blots were washed and signal was detected by enhanced chemiluminescence (ECL) using the LumiGlo substrate (Super Signal West Pico Trial Kit, Pierce, USA). ECL signal was recorded using an imaging system (Bio-Rad, USA) and analyzed with Quantity One software (Bio-Rad, USA). The phosphorylation level of ACC1, AKT and p70S6K was determined by the ratio of P-ACC1 to total ACC1, P-AKT to total AKT and P-p70S6K to total p70S6K, respectively. The expression level of PI3K was determined by the ratio of PI3K to GAPDH.

\section{Statistical analysis}

Data are presented as the means \pm SEM. Data were tested for normal distribution, and statistical significance was assessed by the independent sample t-test using SPSS version 11.0 for Windows (SPSS Inc., Chicago, IL, USA). Data were considered statistically significant if $P<0.05$. The numbers of replicates used for statistics are noted in the Tables and Figures.

\section{Results}

The milk yield and milk composition of lactating goats from treatment and control groups

Different diets had no influence on the dry matter intake (DMI) of goats. However, the milk protein and fat content in the BG goats were significantly higher than those of the control group $(P<0.05)$. In addition, within 20 weeks of treatment, the milk yield, lactose and total solids were higher in the BG goats than that in the control goats (Table 3).

Table 3. Dry matter intake (DMI), milk yield, and milk composition from the two groups of lactating goats.

\begin{tabular}{lccc}
\hline & \multicolumn{2}{c}{ Treatment } & P-value \\
\cline { 2 - 4 } Item & Control & BG & 0.82 \\
\hline DMI, $\mathrm{kg} / \mathrm{d}$ & $1.80 \pm 0.13$ & $1.98 \pm 0.02$ & 0.10 \\
Milk & & & $0.03^{*}$ \\
Yield, $\mathrm{kg} / \mathrm{d}$ & $1.00 \pm 0.02$ & $1.38 \pm 0.03$ & $0.05^{*}$ \\
Fat content, \% & $3.24 \pm 0.10$ & $4.2 \pm 0.08$ & 0.81 \\
Protein, \% & $2.82 \pm 0.05$ & $3.80 \pm 0.01$ & 0.77 \\
Lactose, \% & $4.32 \pm 0.38$ & $4.75 \pm 0.29$ & $13.23 \pm 0.22$ \\
Total solids, \% & $12.10 \pm 0.23$ & & \\
\hline
\end{tabular}

Data are presented as the means \pm SEM ( $n=6 /$ group). $* P<0.05$ indicates statistically significant differences when compared with the control group.

\section{Rumen $\mathrm{pH}$, LPS content in the rumen and plasma}

The dynamic $\mathrm{pH}$ curve in the $\mathrm{BG}$ group was higher than that in the control group during the long-term experiment. However, it showed that a $\mathrm{pH}$ value under 5.6 lasted for $3 \mathrm{~h}$ in the control group, which indicated that SARA was successfully induced (Fig. 1). The LPS concentration in the rumen fluid and plasma was significantly lower in the BG group than that in the control group $(P<0.05$, Table 4$)$.

The plasma biochemical parameters of lactating goats from treatment and control groups

As shown in Table 4, the plasma content of NEFA and INS were significantly higher in the BG group compared to the control group $(P<0.05)$. Meanwhile, we found that the concentrations of plasma glucose, TG, glucagon, and total cholesterol were higher in the BG goats compared to the control goats, although the difference was not statistically significant.

$B G$ diet increased the production of TG and NEFA in the liver of lactating goats

We next examined nutrition substances in the plasma obtained from the hepatic and portal veins of both treatment groups. We calculated the ratio of portal vein levels: hepatic vein levels $(\mathrm{H}-\mathrm{P})$. If $\mathrm{H}-\mathrm{P}>0$, it indicates that more nutrition substances are produced in the liver than those that enter the blood. Conversely, if $\mathrm{H}-\mathrm{P}<0$, it 
indicates that nutrition substances are consumed in the liver, suggesting that NEFA is catabolize there. Our measurements showed that NEFA was significantly higher in BG goats when compared to control goats $(P<0.05$, Table 5). This suggested that more milk fat precursors were produced in the liver. In addition, the total cholesterol was consumed in the livers of both $\mathrm{BG}$ and control goats.

$B G$ diet treatment regulated key enzymes required for lipid metabolism in the livers of goats

Sterol regulatory element binding protein-1c (SREBP-1c) is a key regulator of intracellular lipid metabolism, including the uptake and synthesis in the liver. We therefore examined expression of SREBP-1c mRNA and some of its known downstream targets in BG and control goats (Fig. 2A). We found that SREBP-1c expression in the BG goats was significantly higher than that in the control goats $(P<0.05)$. The expression of downstream targets of SREBP-1c, such as stearoyl-CoA desaturase (SCD-1), ACC1, and fatty acid synthetase (FAS) were also increased by the $\mathrm{BG}$ diet. In particular, FAS and ACC1 expression in the BG goats were significantly higher than that in the control goats $(P<0.05)$. Peroxisome proliferator activated receptors $\alpha$ $(\operatorname{PPAR} \alpha)$ is a key transcription factor that controls intracellular lipid oxidation. It likely achieves this by regulating carnitine palmitoyltransferase-1 (CPT-1), carnitine palmitoyltransferase-2 (CPT-2), liver-fatty acid binding protein (L-FABP) and acyl-CoA oxidase (ACO), which are enzymes required for lipid oxidation in the liver. Here, we found that the mRNA expression of PPAR $\alpha$, CPT-1, CPT-2, L-FABP, and ACO were decreased in the $\mathrm{BG}$ goats compared to expression in the goats. In particular, expression of PPAR $\alpha$, CPT-1, L-FABP and ACO were significantly lower than that in the controls $(P<0.05$; Fig. 2B). However, CPT-2 expression in the $\mathrm{BG}$ goats was not significantly different from that in the controls.

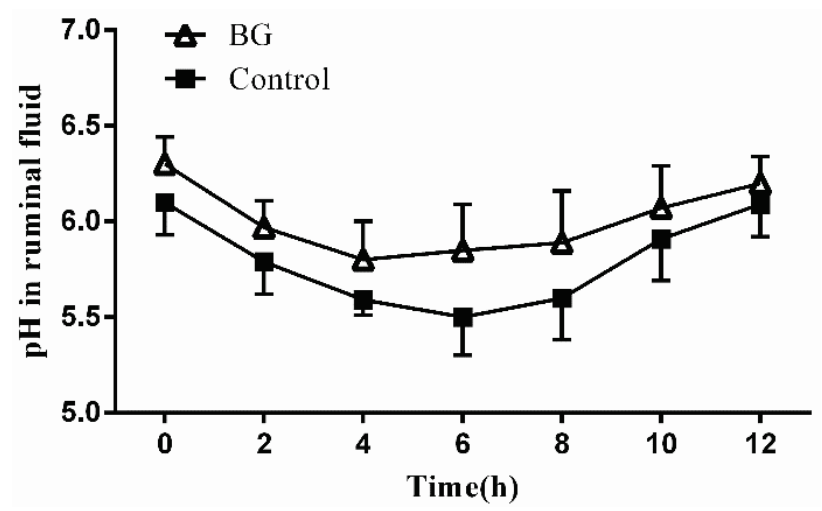

Fig. 1. $\mathrm{pH}$ value in ruminal fluid after 20 weeks feeding regime. Data are presented as the means \pm SEM ( $n=6 /$ group). $* P<0.05$ indicates statistically significant differences when compared with the control group.

Table 4. Effects of the BG diet on plasma indicators of lactating goats.

\begin{tabular}{lccc}
\hline Item & Control & BG & P-value \\
\hline Glucose (mmol/l) & $3.34 \pm 0.25$ & $3.44 \pm 0.29$ & 0.56 \\
Nonesterified fatty acid (nmol/l) & $1.34 \pm 0.10$ & $1.98 \pm 0.09$ & $0.04^{*}$ \\
Triacylglycerol (mmol/l) & $0.34 \pm 0.02$ & $0.41 \pm 0.04$ & 0.67 \\
Insulin (mIU/l) & $13.81 \pm 0.10$ & $19.43 \pm 0.18$ & $0.03^{*}$ \\
Glucagon (pg/ml) & $457.43 \pm 45.96$ & $525.81 \pm 38.23$ & 0.20 \\
Total cholesterol (mmol/l) & $0.94 \pm 0.05$ & $0.96 \pm 0.06$ & 0.32 \\
LPS (EU/ml) & & & $0.02^{*}$ \\
Rumen fluid & $42,550 \pm 136$ & $23340 \pm 134$ & $0.02^{*}$ \\
Jugular vein & $3.76 \pm 0.33$ & $1.82 \pm 0.14$ & \\
\hline
\end{tabular}

Data are presented as the means \pm SEM ( $n=6 /$ group). $* P<0.05$ indicates statistically significant differences when compared with the control group.

We also investigated the extent of P-ACC1 protein. We found that it was significantly lower in the BG goats compared to the levels in the control goats by Western blotting $(P<0.05$, Fig. 3). It is indicated that
ACC1 activity was significantly higher in the BG groups than in the control groups. This is consistent with our previous observation that ACC1 mRNA expression increases in BG goats. 
Table 5. Effect of the BG diet on plasma indicators in lactating goats.

\begin{tabular}{|c|c|c|c|}
\hline & \multicolumn{2}{|c|}{ Treatment } & \multirow{2}{*}{$P$-value } \\
\hline & Control & BG & \\
\hline \multicolumn{4}{|l|}{ Hepatic vein $(H)$} \\
\hline Triglyceride (mmol/l) & $0.16 \pm 0.03$ & $0.15 \pm 0.03$ & 0.15 \\
\hline Nonesterified fatty acid (mmol/l) & $1.42 \pm 0.03$ & $1.78 \pm 0.02$ & $0.03 *$ \\
\hline Total cholesterol ( $\mathrm{mmol} / \mathrm{l})$ & $0.61 \pm 0.09$ & $0.55 \pm 0.03$ & 0.21 \\
\hline \multicolumn{4}{|l|}{ Portal vein $(P)$} \\
\hline Triglyceride (mmol/l) & $0.16 \pm 0.01$ & $0.13 \pm 0.01$ & 0.41 \\
\hline Nonesterified fatty acid (mmol/l) & $1.67 \pm 0.04$ & $1.73 \pm 0.03$ & 0.80 \\
\hline Total cholesterol (mmol/l) & $0.86 \pm 0.05$ & $0.84 \pm 0.03$ & 0.33 \\
\hline \multicolumn{4}{|l|}{$(H-P)$} \\
\hline Triglyceride (mmol/l) & $0.00 \pm 0.01$ & $0.02 \pm 0.02$ & 0.16 \\
\hline Nonesterified fatty acid (mmol/l) & $-0.25 \pm 0.02^{1}$ & $0.05 \pm 0.01^{2}$ & $0.02 *$ \\
\hline Total cholesterol (mmol/l) & $-0.25 \pm 0.03$ & $-0.29 \pm 0.03$ & 0.17 \\
\hline
\end{tabular}

${ }^{1} \mathrm{H}-\mathrm{P}<0$ represents a higher nutritional substance concentration in the portal vein blood but a lower nutritional substance concentration in the hepatic vein blood, which indicates that the nutritional substances were consumed by the liver. ${ }^{2} \mathrm{H}-\mathrm{P}>0$ represents a lower nutritional substance concentration in the portal vein blood but a higher nutritional substance concentration in the hepatic vein blood, which indicates that the nutritional substances were produced in the liver. Data are presented as the means \pm SEM ( $n=6 / g r o u p$ ), $* P<0.05$ indicates statistically significant differences when compared with the control group.

A

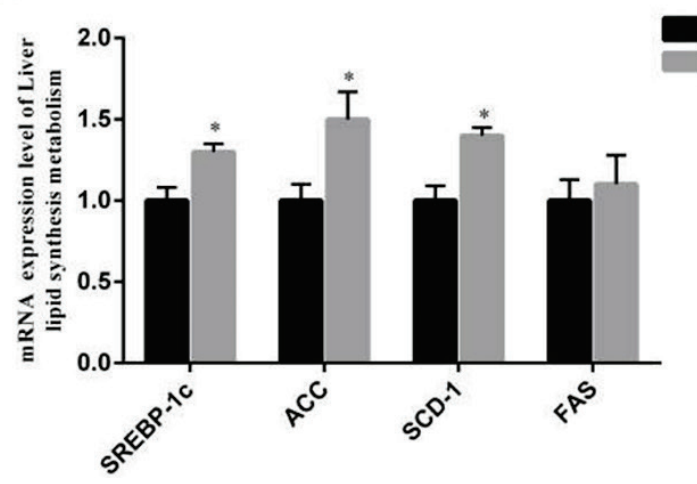
control BG
B

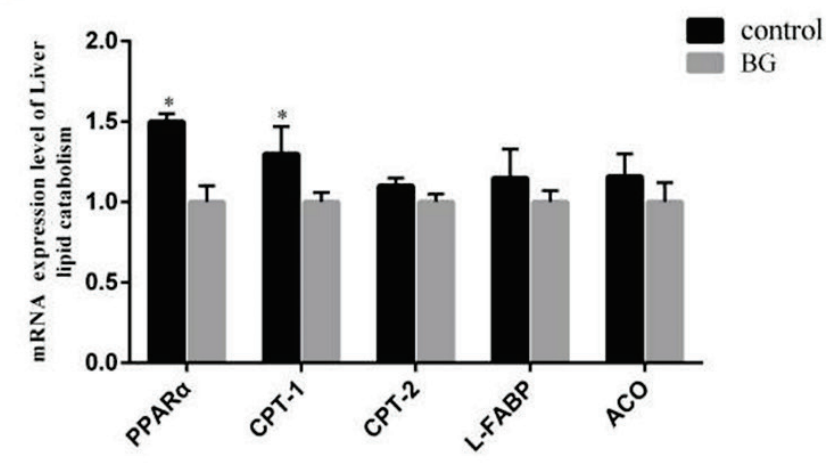

Fig. 2. Effects of the BG diet on the expression of liver lipid metabolism in lactating goats. (A) The lipid synthesis genes involved in sterol regulatory element-binding protein-1c (SREBP-1c), fatty acid synthetase (FAS), acetyl-CoA carboxylase 1 (ACC1), and stearoylCOA desaturase 1 (SCD-1) were measured in the liver tissue. (B) The lipid catabolism genes involved in peroxisome proliferatoractivated receptor a (PPARa), carnitine palmitoyl transferase-1 (CPT-1), carnitine palmitoyl transferase-2 (CPT-2), liver-fatty acidbinding protein (L-FABP) and acyl-COA oxidase (ACO) were measured in the liver tissue. GAPDH was used as the control. The experiments were repeated three times. Data are presented as the means \pm SEM ( $n=6 /$ group). $* P<0.05$ indicates statistically significant differences when compared with the control group.

The BG diet treatment modulated the PI3K/AKT-SREBP1c signaling pathway

During the course of our earlier experiments, we observed that INS levels in the plasma were significantly higher in goats treated with the buffering agent. To further explore a potential mechanism for how the $\mathrm{BG}$ diet regulates expression of key liver enzymes, we next examined the activity of the PI3K/AKT signaling pathway. The results indicated that the mRNA expression of insulin receptor (INSR) and insulin receptor substrates (IRS) were significantly higher in the BG goats compared to the levels in the control goats $(P<0.05$, Fig. 4$)$. We also found that levels of PI3K, P-AKT, and P-p70S6K protein in the $\mathrm{BG}$ goats were significantly higher than those in the control goats by Western blotting $(P<0.05$, Figs 5A-C). This suggested that the INS-PI3K/AKTSREBP-1c signaling pathway was activated following treatment with the BG diet of lactating goats. 
Control

BG

\section{P-ACC1 $280 \mathrm{KDa}$ \\ T-ACC1 $280 \mathrm{KDa}$ \\ GAPDH $37 \mathrm{KDa}$}

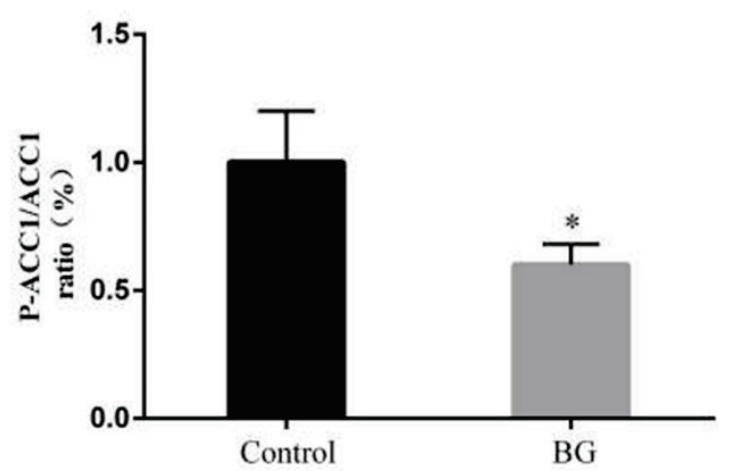

Fig. 3. Effects of the $B G$ diet on the expression of acetyl-CoA carboxylase 1 ( $A C C 1$ ) protein in the liver of lactating goats. The experiments were repeated three times. Data are presented as the means \pm SEM ( $n=6 /$ group). $* P<0.05$ indicates statistically significant differences when compared with the control group.

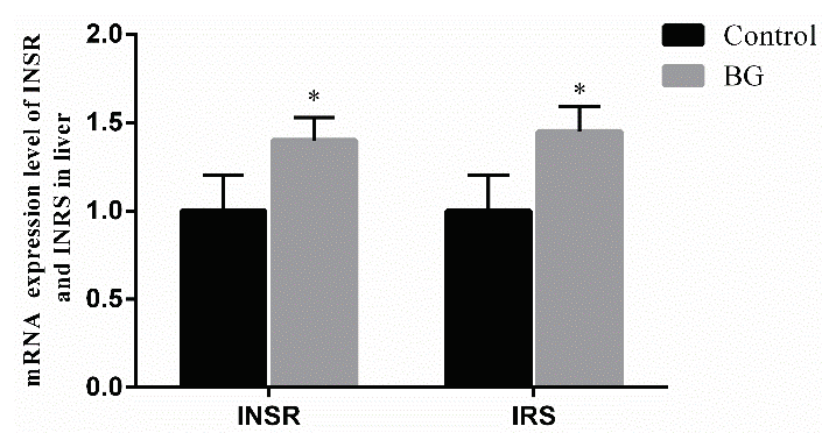

Fig. 4. Effects of the $B G$ diet on the expression of liver insulin receptor (INSR) and insulin receptor substrates (IRS) genes in lactating goats. The experiments were repeated three times. Data are presented as the means \pm SEM ( $n=6 /$ group). $* P<0.05$ indicates statistically significant differences when compared with the control group.

\section{Discussion}

In recent years, intensive production systems for ruminants have encouraged the use of the $\mathrm{HC}$ diet or easily fermentable carbohydrate diet to support high milk yields or rapid weight gain. Although this feeding practice can enhance economic efficiency in the shortterm, the feeding of $\mathrm{HC}$ diet leads to the translocation of LPS from the digestive system into the circulating blood. As a result, SARA often occurs during the periods of early and mid-lactation in dairy production herds. Due to the rapid fermentation and the accumulation of volatile fatty acids in the rumen, as well as the lactic acid, the value of rumen $\mathrm{pH}$ markedly decreased and prolonged for long time (Garrett et al. 1999). Moreover, previous studies have reported that feeding a high-grain diet could cause the SARA and induce the depression of milk fat (Xu et al. 2015).

The $\mathrm{NaHCO}_{3}$ could increase the buffering capacity and prevent the acidosis in rumen. Diets with $\mathrm{NaHCO}_{3}$ did not result in as great a drop of rumen $\mathrm{pH}$, and rumen $\mathrm{pH}$ was more stable for the post feeding (Snyder et al. 1983). Previous studies indicated that the addition of $\mathrm{NaHCO}_{3}$ to a restricted-roughage rations could be given to lactating cows to increase the content of milk fat (Emery et al. 1965). It is well documented that dietary addition of $\mathrm{C}_{4} \mathrm{H}_{7} \mathrm{NaO}_{2}$ could promote development of the rumen mucosa and health status of young dairy cows (Sander et al. 1959). Previous studies indicated that the addition of $\mathrm{C}_{4} \mathrm{H}_{7} \mathrm{NaO}_{2}$ to a $\mathrm{HC}$ diet could be given to lactating goats to decrease the content of LPS in rumen (Dai et al. 2017). In this study, the control goats fed a HC diet for 20 weeks exhibited a lower ruminal $\mathrm{pH}$, which decreased to $<5.6$ and
A

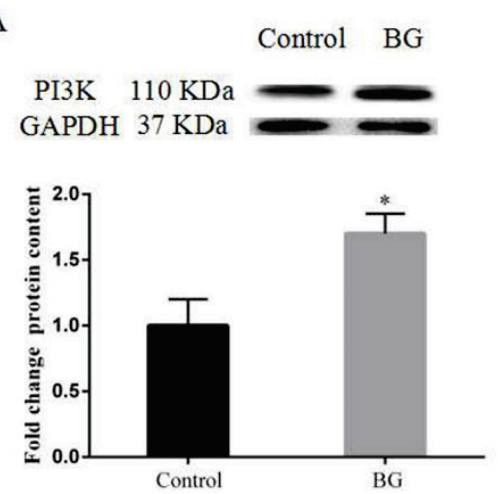

B
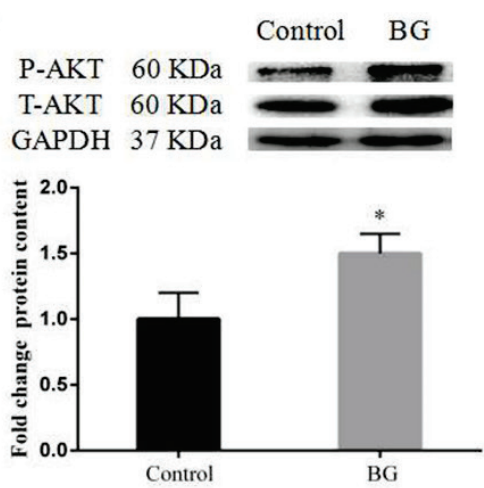

$\mathrm{C}$

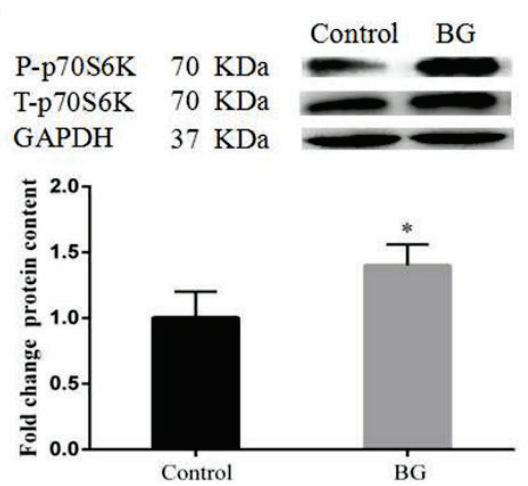

Fig. 5. (A) Effects of the BG diet on the expression of phosphatidylinositol 3-kinase (PI3K), (B) protein kinase $B$ (AKT) and (C) ribosomal protein S6 kinase (p70S6K) proteins in the liver of lactating goats. The experiments were repeated three times. Data are presented as the means \pm SEM ( $n=6 /$ group). $* P<0.05$ indicates statistically significant differences when compared with the control group. 
persisted for more than $3 \mathrm{~h}$ per day after feeding. According to the definition of experimental SARA, the control goats were suffered SARA disease. However, we found that the $\mathrm{pH}$ in the rumen fluid of BG-fed goats was much higher than that of control goats. The concentrations of LPS in the rumen and jugular were also markedly decreased, indicating that the BG diet stabilized ruminal $\mathrm{pH}$ and prevented the release of LPS. Moreover, the goats that consumed the $\mathrm{HC}$ diet with the added buffering agent displayed a higher milk fat content, which was consistent with the study conducted in dairy cows. However, the mechanism of milk fat up-regulated still requires further study.

NEFA is one of the most important precursors in milk fat. Previous studies have reported that feeding a high-concentrate diet could cause the depression of milk fat with the decline of NEFA in blood. It is well documented that with the increasing of NEFA content in blood, the absorbed quantity applied to milk fat synthesis was also elevated in mammary (Kadegowda et al. 2017, Li et al. 2017). Furthermore, we quantified the precursors for milk fat synthesis. The results showed that the levels of NEFA in the plasma of the BG goats were significantly higher than that in the control goats. In ruminants, the liver is the major site for gluconeogenesis and lipogenesis, which provides the substrate precursors to the mammary gland for milk production (Dorland et al. 2012). Therefore, the concentration of these precursors in the blood have an important influence on milk fat synthesis. In order to further study the changes observed in milk fat precursors, we examined the dynamics of NEFA production in the liver by assaying plasma obtained from the hepatic vein and portal vein. The results suggested that more NEFA was produced from the livers of BG goats compared to that in control goats. However, the relationship between increased plasma NEFA and liver still warrants further investigation in this study.

Peroxisome proliferator-activated receptors (PPARs) involved in the transport of TG in the blood, cellular fatty acid uptake, and mitochondrial beta oxidation (Pettinelli et al. 2011). PPARs have three subtypes including PPAR $\alpha$, PPAR $\beta$, and PPAR $\gamma$. PPAR $\alpha$ has an important role in the regulation of mitochondrial and peroxisomal fatty acid oxidation in ruminants, including modulation of four downstream targets, ACO, CPT-1, CPT-2 and L-FABP (Barger and Kelly 2000). Sterol regulatory element binding proteins (SREBPs) are transcription factors that activate genes involved in lipogenesis and fatty acid synthesis (Shimano 2002). SREBP-1c is one member of this family, and it may regulate many genes involved in lipid synthesis and deposition (Horton et al. 2003), such as ACC1, SCD-1, and FAS, which are all required for fatty acid synthesis in white adipose tissue, the liver, skeletal muscle, and other tissues (Li et al. 2018). To explore the mechanisms by which the buffering agent treatment improves milk fat synthesis, we analyzed the expression of key transcription factors and enzymes required for lipid metabolism regulation in the liver. The results showed that the buffering agent treatment inhibited mRNA expression of PPAR $\alpha$, CPT-1, CPT-2, L-FABP and ACO. In contrast, the mRNA levels of SREBP-1c and its downstream protein targets SCD-1, ACC1, and FAS were elevated. Taken together, these results suggest that the buffering agent treatment promotes NEFA uptake and synthesis, and inhibits NEFA catabolism by regulating the expression of key liver enzymes found in lactating goats. Simply put, the buffering agent treatment reduces NEFA consumption while increasing its accumulation in liver. This may be useful for developing ways to generate more synthetic precursors for producing milk fat in the mammary gland, and could also explain why milk fat synthesis is increased by treatment with the buffering agent.

INS is a anabolic hormone secreted by the pancreatic beta cells, it is transported to the liver through the blood circulation, and binds to INSR on the liver to play the physiological effect by INS signaling pathway (McAtee and Trenkle 1971). Previous studies have also shown that INS promotes lactation and regulates liver lipid metabolism to increase the synthesis of NEFA in the liver while inhibiting NEFA catabolism through the PI3K signaling pathway (Shimomura et al. 2000, Hanssen et al. 2015). SREBP-1c is a major regulator of lipid production, it is induced by INS, and it can promote the expression of genes related to lipid synthesis through PI3K signaling pathway (Yoshikawa et al. 2000, Dong et al. 2010). Furthermore, the increase in expression of SREBP-1c was found to be achieved via modulation of the PI3K signaling pathway after adding INS to hepatic cells (Foretz et al. 1999). Lipid synthesis and metabolism likely increases as a result of SREBP-1c activity induced by the PI3K-AKT signaling pathway (Porstmann et al. 2005). To further explore the mechanisms by which the buffering agent treatment regulated liver enzyme expression, we studied the activity of the INS-PI3K/AKT-SREBP-1c signaling pathway. In the 
present study, the results showed that the buffering agent treatment increased protein expression of PI3K, AKT in liver. In addition, the plasma INS levels in the BG group were also higher. Therefore, we verified that this pathway is activated in the livers of goats that received the buffering agent. Furthermore, the SREBP-1c pathway mediates the observed effects on NEFA metabolism by enhancing fatty acid synthesis and inhibiting oxidation in the livers of lactating goats.

In summary, we systematically investigated the effects of a buffering agent on the metabolism of lipid in the livers of lactating goats fed with a high-concentrate diet and found that NEFA precursors were produced in the liver and increased in plasma. Furthermore, the plasma INS levels were also increased in the BG goats: elevated INS increases PI3K/AKT phosphorylation and activity. Activated PI3K/AKT promotes the expression and transcriptional activity of SREBP-1c, thereby downregulating the expression of the lipid synthesis genes and promoting lipid synthesis. Thus, long-term BG diet feeding may lead to the up-regulated expression of lipid synthesis genes and a increase in the NEFA content in the blood via the INS-PI3K/AKT-SREBP-1c signaling pathway. Meanwhile, the increased NEFA concentration in the blood of goats fed a BG diet may explain the up-regulated in milk fat in these lactating goats.

\section{Conflict of Interest}

There is no conflict of interest.

\section{Acknowledgements}

This work was supported by the $13^{\text {th }}$ Five-Year State Key Development Program (2017YFD0500505), the National "973" Project on Milk Composition Precursors Redistribution Mechanism and Epigenetic Mechanism in Liver (grant number 2011CB100802), the Priority Academic Program Development of Jiangsu Higher Education Institutions (PAPD).

\section{References}

BELL AW: Lipid metabolism in liver and selected tissues and in the whole body of ruminant animals. Prog Lipid Res 18: 117-164, 1979.

BERTHELIER-LUBRANO C, SPIEGELMAN B, KIM JB, FERRÉ P: ADD1/SREBP-1c is required in the activation of hepatic lipogenic gene expression by glucose. Mol Cell Biol 19: 3760-3768, 1999.

BARGER PM, KELLY DP: PPAR signaling in the control of cardiac energy metabolism. Trends Cardiovasc Med 10: 238-245, 2000.

BOJADŽIEV G: PKB/Akt induces transcription of enzymes involved in cholesterol and fatty acid biosynthesis via activation of SREBP. Oncotarget 24: 6465-6481, 2005.

BAUMAN DE, HARVATINE KJ, LOCK AL: Nutrigenomics, rumen-derived bioactive fatty acids, and the regulation of milk fat synthesis. Annu Rev Nutr 31: 299-319, 2011.

CHEN Y, OBA M, GUAN LL: Variation of bacterial communities and expression of Toll-like receptor genes in the rumen of steers differing in susceptibility to subacute ruminal acidosis. Vet Microbiol 159: 451-459, 2012.

DONG XY, TANG SQ: Insulin-induced gene: a new regulator in lipid metabolism. Peptides 31: 2145-2150, 2010.

DUANMU Y, CONG R, TAO S, TIAN J, DONG H, ZHANG Y, NI Y, ZHAO R: Comparative proteomic analysis of the effects of high-concentrate diet on the hepatic metabolism and inflammatory response in lactating dairy goats. J Anim Sci Biotechnol 7: 5, 2016.

DAI H, LIU X, YAN J, AABDIN ZU, BILAL MS, SHEN X: Sodium butyrate ameliorates high-concentrate dietinduced inflammation in the rumen epithelium of dairy goats. J Agric Food Chem 65: 596-604, 2017.

EMERY RS, BROWN LD, BELL JW: Correlation of milk fat with dietary and metabolic factors in cows fed restrictedroughage rations supplemented with magnesium oxide or sodium bicarbonate. J Dairy Sci 48: 1647-1651, 1965.

GARRETT EF, PEREIRA MN, NORDLUND KV, ARMENTANO LE, GOODGER WJ, OETZEL GR: Diagnostic methods for the detection of subacute ruminal acidosis in dairy cows. J Dairy Sci 82: 1170-1178, 1999.

GOZHO GN, PLAIZIER JC, KRAUSE DO, KENNEDY AD, WITTENBERG KM: Subacute ruminal acidosis induces ruminal lipopolysaccharide endotoxin release and triggers an inflammatory response. $J$ Dairy Sci 88: 1399-1403, 2005. 
GORKA P, KOWALSKI ZM, PIETRZAK P, KOTUNIA A, KILJANCZYK R, FLAGA J, HOLST JJ, GUILLOTEAU P, ZABIELSKI R: Effect of sodium butyrate supplementation in milk replacer and starter diet on rumen development in calves. J Physiol Pharmacol 60 (Suppl 3): 47-53, 2009.

HORTON JD, SHAH NA, WARRINGTON JA, ANDERSON NN, PARK SW, BROWN MS, GOLDSTEIN JL: Combined analysis of oligonucleotide microarray data from transgenic and knockout mice identifies direct SREBP target genes. Proc Natl Acad Sci U S A 100: 12027-12032, 2003.

HANSSEN MJ, HOEKS J, BRANS B, VAN DER LANS AA, SCHAART G, VAN DEN DRIESSCHE JJ, JÖRGENSEN JA, BOEKSCHOTEN MV, HESSELINK MK, HAVEKES B, KERSTEN S, MOTTAGHY FM, VAN MARKEN LICHTENBELT WD, SCHRAUWEN P: Short-term cold acclimation improves insulin sensitivity in patients with type 2 diabetes mellitus. Nat Med 21: 863-865, 2015.

ISLAM SMS, HOSSAIN MA, HASHIM MMA, SARKER MSA, PAUL AK: Effects of sodium bicarbonate on induced lactic acidosis in Black Bengal goats. Wayamba J Anim Sci 6: 1044-1057, 2014.

KRISTENSEN NB: Splanchnic metabolism of volatile fatty acids in the dairy cow. Anim Sci 80: 3-10, 2005.

KADEGOWDA AKG, PIPEROVA LS, DELMONTE P, ERDMAN RA: Abomasal infusion of butterfat increases milk fat in lactating dairy cows. J Dairy Sci 91: 2370-2379, 2008.

KHAFIPOUR E, KRAUSE DO, PLAIZIER JC: A grain-based subacute ruminal acidosis challenge causes translocation of lipopolysaccharide and triggers inflammation. J Dairy Sci 92: 1060-1070, 2009.

LIN L, YANG C, XIE Z, ZHANG Y: A high-concentrate diet induced milk fat decline via glucagon-mediated activation of AMP-activated protein kinase in dairy cows. Sci Rep 7: 44217, 2017.

LI L, HE M, XIAO H, LIU X, WANG K, ZHANG Y: Acetic acid influences BRL-3A cell lipid metabolism via the AMPK signalling pathway. Cell Physiol Biochem 45: 2021-2030, 2018.

MCATEE JW, TRENKLE A: Metabolic regulation of plasma insulin levels in cattle. J Anim Sci 33: 438-442, 1971.

MENG J, WANG HQ, CAO J: Nutritional composite buffer effect on the performance of dairy cow. Ningxia J Agricult Forestry Sci Technol 3: 49-50, 1999.

PENNINGTON RJ: The metabolism of short-chain FA in the sheep. 1. Fatty acid utilization and ketone body production by rumen epithelium and other tissues. Biochem J 51: 251, 1952.

PLAIZIER JC, KRAUSE DO, GOZHO GN, MCBRIDE BW: Subacute ruminal acidosis in dairy cows: the physiological causes, incidence and consequences. Vet J 176: 21-31, 2008.

PETTINELLI P, OBREGÓN AM, VIDELA LA: Molecular mechanisms of steatosis in nonalcoholic fatty liver disease. Nutr Hosp 26: 441-450, 2011.

SNYDER TJ, ROGERS JA, MULLER LD: Effects of $1.2 \%$ sodium bicarbonate with two ratios of corn silage:grain on milk production, rumen fermentation, and nutrient digestion by lactating dairy cows. J Dairy Sci 66: 1290-1297, 1983.

SHIMOMURA I, MATSUDA M, HAMMER RE, BASHMAKOV Y, BROWN MS, GOLDSTEIN LJ: Decreased IRS-2 and increased SREBP-1c lead to mixed insulin resistance and sensitivity in livers of lipodystrophic and ob/ob mice. Mol Cell 6: 77-86, 2000.

SANDER EG, WARNER RG, HARRISON HN, LOOSLI JK: The stimulatory effect of sodium butyrate and sodium propionate on the development of rumen mucosa in the young calf. J Dairy Sci 42: 1600-1605, 1959.

VAN DORLAND HA, SADRI H, MOREL I, BRUCKMAIER RM: Coordinated gene expression in adipose tissue and liver differs between cows with high or low FFA concentrations in early lactation. J Anim Physiol Anim Nutr 96: 137-147, 2012.

XU T, HUI T, CHANG G, KAI Z, LEI X, SHEN X: Lipopolysaccharide derived from the rumen down-regulates stearoyl-CoA desaturase 1 expression and alters fatty acid composition in the liver of dairy cows fed a high-concentrate diet. BMC Vet Res 11: 1, 2015.

YOSHIKAWA T, IHIRA M, SUZUKI K, SUGA S, IIDA K, SAITO Y, ASONUMA K, TANAKA K, ASANO Y: Human herpesvirus 6 infection after living related liver transplantation. J Med Virol 62: 52-59, 2000.

ZEBELI Q, DIJKSTRA J, TAFAJ M, STEINGASS H, AMETAJ BN, DROCHNER W: Modeling the adequacy of dietary fiber in dairy cows based on the responses of ruminal $\mathrm{pH}$ and milk fat production to composition of the diet. J Dairy Sci 91: 2046-2066, 1999. 
ZEBELI Q, AMETAJ BN: Relationships between rumen lipopolysaccharide and mediators of inflammatory response with milk fat production and efficiency in dairy cows. J Dairy Sci 92: 3800-3809, 2009. 